\title{
MODELO DE ÉXITO DEL CURSO TALLER DE TITULACIÓN POR TESIS EN MEDICINA HUMANA: PUBLICACIÓN DE REPERCUSIÓN INTERNACIONAL
}

\author{
SUCCESS MODEL OF THE WORKSHOP CERTIFICATION IN HUMAN MEDICINE: \\ PUBLICATION OF INTERNATIONAL IMPACT \\ Jhony A. De La Cruz-Vargas ${ }^{1, a, b, c}$, Lucy E. Correa López ${ }^{2, d}$, \\ María del Socorro A. Gutiérrez Vda. de Bambaren ${ }^{3}$ Hugo H. Sánchez Carlessi ${ }^{4}$ \\ Instituta de Investigación en Ciencias Biamédicas de la Universidad Ricarda Palma.
}

Promover la Investigación en Estudiantes de Medicina y elevar la producción científica en las universidades del Perú y de Latinoamérica es una prioridad y una necesidad'. Es un honor compartir con ustedes que recientemente publicamos en la prestigiosa revista Educación Medica, de Elsevier, indexada en Scopus, el articulo científico que resume la experiencia y el modelo de éxito del Curso Taller de Tesis que se dicta en la Facultad de Medicina Humana de la Universidad Ricardo Palma: Promoting research in medical students and increasing scientific production in universities: Experience of the Undergraduate Thesis Workshop Course ${ }^{2}$.

La tesis de pregrado representa el trabajo académico con rigor científico, considerado como el primer paso serio de los estudiantes universitarios en el campo de la investigación, que según la nueva ley universitaria 30220 vigente en el Perú, constituye un requisito indispensable para obtener el titulo universitario².

- Este articulo publicado, reúne algunas características esenciales:

- Aborda una temática inherente a la Educación Medica en las Universidades

- Presenta el Rol fundamental de la Universidad en la investigación y la producción científica.

- Muestra el modelo de éxito del Curso Taller de Titulación por Tesis en Medicina, y lo comparte a nivel internacional.

- Describe de manera sistematizada el diseño y aplicación del Curso Taller de Titulación por Tesis y su eficacia en la producción de tesis en la Facultad de Medicina Humana.

- Confiere presencia y visibilidad a la Universidad Ricardo Palma, a través de su Instituto de Investigación en Ciencias Biomédicas.

Algunas tendencias que muestran el paper son: El área clínica aparece como la mas elegida entre los estudiantes de medicina, luego la quirúrgica y salud publica. El promedio obtenido en mas de 450 tesis sustentadas es de $16.17 \mathrm{y}$ el promedio de originalidad es de $11.29 \%$.

Un aspecto interesante son las herramientas practicas e innovadoras que provee el Curso Taller de Titulación por Tesis: Guia y plantilla del proyecto de investigación, plantilla del borrador de tesis, manual de búsqueda sistemática, matriz de prioridades de investigación nacional e institucional 2015-2021, calculador practico del tamaño

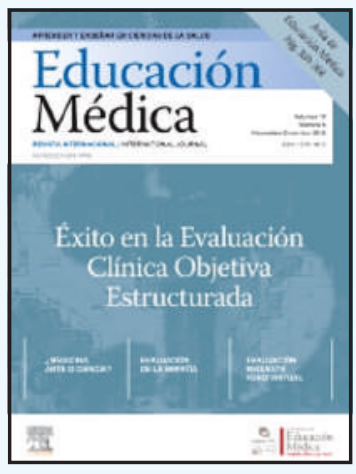

Director General del INICIB, URP, Lima-Perú.

Instituto de Investigación en Ciencias Biomédicas, Universidad Ricardo Palma, Lima-Perú.

${ }^{3}$ Decana de la Facultad de Medicina humana, Universidad Ricardo Palma (URP), Lima-Perú.

${ }^{4}$ Vicerrector de Investigación de la Facultad de Medicina humana, Universidad Ricardo Palma (URP), Lima-Perú.

Especialista en Oncología Medica.

Maestría en Investigación Clínica.

Doctorado en Medicina.

Economista, MBA.

Citar como: Jhony A. De La Cruz-Vargas, Lucy E. Correa López, María del Socorro A. Gutiérrez Vda. de Bambaren, Hugo H. Sánchez Carlessi. Modelo de éxito del curso taller de titulación por tesis en medicina humana: Publicación de repercusión internacional. [Editorial]. Rev. Fac. Med. Hum. 2019;19(1):13-15. (Enero 2019). DOI 10.25176/RFMH.v19.n1.1787 


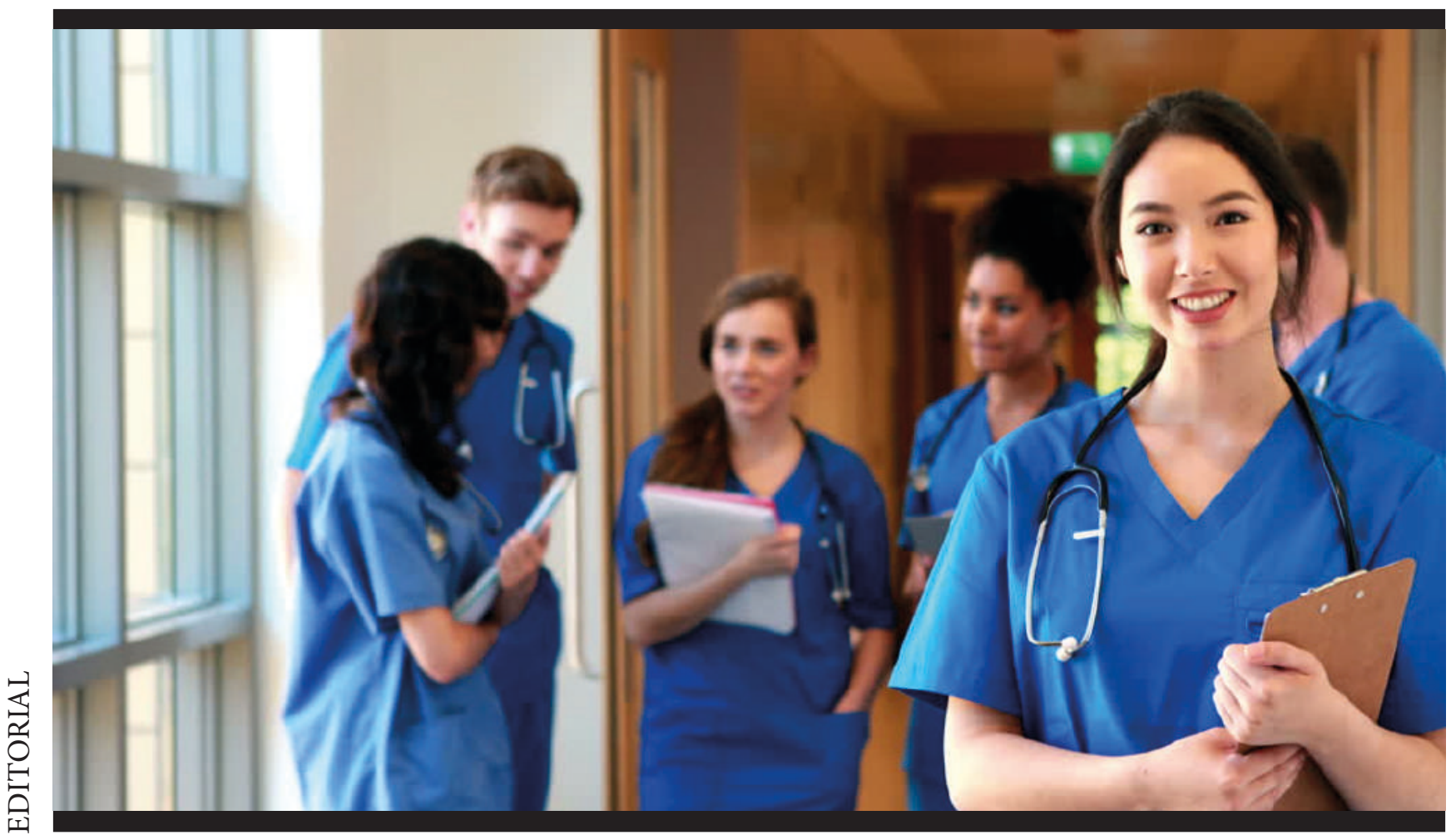

de la muestra, consulta al banco de tesis sustentadas, guia el estilo Vancouver, guia de sustentación de tesis, plantilla de elaboración del articulo derivado de su tesis.

El uso de las tecnologías de la información forma parte fundamental de este modelo de éxito, la aplicación interactiva del Classroom, grupos de Whast App, y el uso del sistema de reporte de originalidad Turnitin en todas las tesis, contribuyo a la originalidad y fomentar la honestidad académica en estudiantes universitarios.

Promover la investigación en el pregrado resulta esencial, por diversas razones. Los estudiantes de medicina desempeñan un papel en la producción de investigación y deben estar presentes en los proyectos financiados, tal como lo solicitan CONCYTEC y la URP. El desarrollo de pensamiento critico, capacidad para comprender y evaluar las publicaciones desarrollo de competencias escritas y trabajo en equipo, iniciar en la capacidad de comunicación de datos científicos. Todo esta respalda su actitud presente y futura de desarrollo académico. Con gran satisfacción podemos ver como nuestros estudiantes de medicina (SOCEMURP) vienen ocupando lugares destacados a nivel nacional, tanto en publicaciones como en liderazgo y participación. Alentar y fomentar este desarrollo es una función ineludible de la Universidad en todos sus niveles.

Cuando iniciamos el primer Curso Taller de Titulación por Tesis en el año 2015, uno de los retos era la no disponibilidad de docentes investigadores con experiencia en asesorar y dirigir tesis. Al año 2018 hemos completado el IV Curso de Titulación por Tesis, el trabajo a sido arduo y hemos crecido en docentes con experiencia en asesorar tesis y en incorporar docentes investigadores con experiencia real para trasmitir a las futuras generaciones medicas. Otro aspecto esencial es el acceso a bases virtuales de información científica y apoyo a las decisiones clínicas, La Facultad de Medicina Humana de la URP esta registrada y tiene acceso a ClinicallKey y resulta deseable contar con SCOPUS y ScienceDirect y Mendeley para la comunidad de docentes y estudiantes de la Universidad Ricardo Palma.

Aun así, queda mucho camino por recorrer, y estamos trabajando para este 2019 tener dos Cursos de Titulación por Tesis, uno de marzo a julio y otro de agosto a noviembre. Este ultimo por primera vez dirigido a estudiantes que disponen de un semestre antes de ingresar a su Internado Medico, situación ideal para realizar el Curso y completar su investigación rumbo a la tesis. Un desafío central es alcanzar niveles de publicación de las tesis en revistas indizadas ${ }^{3}$, cerrando el circulo de investigación y contribuyendo al posicionamiento de la Universidad. Una opción interesante es incorporar la Tesis en formato de articulo científico, como una oportunidad para incrementar la publicación científica universitaria ${ }^{4}$. Generar las condiciones necesarias para alcanzar este desafío en la universidad es tarea de todos. 


\section{Correspondencia: Jhony A. De La Cruz Vargas}

Dirección: INICIB, Facultad de Medicina Humana, Edificio I-208. 2do piso. Avenida Benavides 5440, Surco, Lima-Perú.

Teléfono: 708-0000 / Anexo: 6016

Correo:jhony.delacruzv@urp.pe

\section{REFERENCIAS BIBLIOGRÁFICAS}

1.Manuel Huamán-Guerrero, Jhony A. De La Cruz-Vargas. INICIB: Producción científica, colaboración y crecimiento académico 2016 [Editorial].

Rev. Fac. Med. Hum. 2017;17(1):7-9.

DOI:https://doi.org/10.25176/RFMH.v17.n1.738

2.Jhony A. De La Cruz Vargas, Lucy E. Correa López, Maria del Socorro Alatrista Vda. de Bambaren, Hector H. Sanchez Carlessi y Asesores participantes. Promoting research in medical students and increasing scientific production in universities: Experience of the Undergraduate Thesis Workshop Course. Education Medica Journal. 2018. SCOPUS. DOI 10.1016/j.edumed.2018.06.003
3.T.D. Silva, L.C. da Cunha Aguiar, J. Leta, D.O. Santos, F.S.Cardoso, L.M. Cabral, et al.Role of the undergraduate student research assistant in the new millennium Cell Biol Educ., 3 (2004), pp. 235-240

4.Christoper A. Alarcon-Ruiz1,a, Maria A. Quezada. Publicación de artículos científicos por asesores de tesis de una Facultad de Medicina. Rev Med Hered. 2018; 29:152-157.

DOI: https://doi.org/10.20453/rmh.v29i3.3403

5.Mayta-Tristán Percy. Tesis en formato de artículo científico: oportunidad para incrementar la producción científica universitaria. Acta méd. peruana [Internet]. $2016 \mathrm{Abr}$ [citado 2019 Ene 12] ; 33( 2 ): 95-98.

Disponible en: http://www.scielo.org.pe/scielo.php?script=sci_ arttext\&pid=S1728-59172016000200001\&lng=es.

Consulte la Versión Electrónica de la Revista:

Facultad de Medicina Humana Universidad Ricardo Palma

http://revistas.urp.edu.pe/index.php/RFMH<smiles>C1=[In]CCC1</smiles>

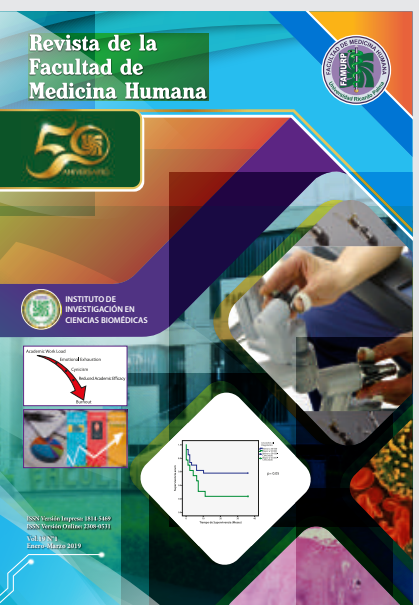

